\title{
Article
}

\section{Ballistic Impact and Virtual Testing of Woven FRP Laminates}

\author{
Ioannis K. Giannopoulos ${ }^{1, * \mathbb{D}}$, Mehdi Yasaee $^{2} \mathbb{D}$ and Nikolaos Maropakis ${ }^{2} \mathbb{D}$ \\ 1 Centre of Aeronautics, School of Aerospace, Transport and Manufacturing, Cranfield University, \\ Cranfield MK43 0AL, UK \\ 2 Centre for Structures, Assembly and Intelligent Automation, School of Aerospace, Transport and \\ Manufacturing, Cranfield University, Cranfield MK43 0AL, UK; m.yasaee@cranfield.ac.uk (M.Y.); \\ nmarop@outlook.com (N.M.) \\ * Correspondence: i.giannopoulos@cranfield.ac.uk
}

Citation: Giannopoulos, I.K.; Yasaee, M.; Maropakis, N. Ballistic Impact and Virtual Testing of Woven FRP Laminates. J. Compos. Sci. 2021, 5, 115. https://doi.org/10.3390/jcs5050115

Academic Editor: Mohammad H. Malakooti

Received: 2 March 2021

Accepted: 19 April 2021

Published: 22 April 2021

Publisher's Note: MDPI stays neutral with regard to jurisdictional claims in published maps and institutional affiliations.

Copyright: (c) 2021 by the authors. Licensee MDPI, Basel, Switzerland. This article is an open access article distributed under the terms and conditions of the Creative Commons Attribution (CC BY) license (https:// creativecommons.org/licenses/by/ $4.0 /)$.

\begin{abstract}
The aim of the work was to investigate the numerical simulations correlation with the experimental behaviour of steel ball high velocity impact onto a $2 \times 2$ twill woven carbon composite laminate. The experimental set up consisted of a pressurised gas-gun able to shot steel ball projectiles onto two different composite plate layup configurations of plates made of the same composite material fabric. Subsequently, the experiments were replicated using the LSDYNA explicit finite element analysis software package. Progressive failure numerical models of two different fidelity levels were constructed. The higher fidelity model was simulating each of the plys of the composite panels separately, tied together using cohesive zone modelling properties. The lower fidelity model consisted of a single layer plate with artificial integration points for each ply. The simulation results came out to be in satisfactory agreement with the experimental ones. While the delamination extent was moderately under predicted by the higher fidelity model, the general behaviour was complying with the experimental results. The lower fidelity model was consistent in representing the damage of the panel during the impact and better predicted the impactor residual velocities due to the better matching of the pane stiffness. Despite the competency of the higher fidelity model to capture the damage of the laminate in a more detailed level, the computational cost was $80 \%$ higher than the lower fidelity case, which rendered that model impractical against the lower fidelity one, to use in larger models representing more substantial or more complex structures.
\end{abstract}

Keywords: impact behaviour; computational modelling; damage mechanics

\section{Introduction}

Fibre reinforced polymer (FRP) composites have significantly increased in usage amongst structures in automotive, aerospace and wind energy industries. FRP composites have even shown advantageous when utilised as reinforcement in rubberised concrete sleepers in railway applications [1]. The main advantages of FRP composite materials for structural applications is their excellent stiffness and strength to weight ratio as well as corrosion and fatigue resistance [2] benefits over metallic counterparts. Despite their superior properties in the direction of the fibre reinforcement, laminated composites are weak in the out-of-plane-strength. That makes them susceptible to failure under transverse static and dynamic loading which are the major concerns in FRP composite laminated structures design [3]. Due to their high speed of service, such structures are occasionally subjected to high velocity foreign object impacts. This can include debris from the runway hitting an aircraft during landing or take-off or floating parts in the track during an automotive race striking the vehicle. Structural integrity justification has to take into consideration all such effects before setting a product in service. However, the experimental route is rather costly and hardly an easily reproducible way of testing and characterising the behaviour of various materials and design solutions. Industry has turned its focus into partially employing numerical simulations for product certification. 
Various simulation methods have been developed for impact on FRP composites, most of them in the micro and mesoscale level. To achieve a correct impact response of an FRP composite plate, the simulation procedure must be capable to capture different failure mechanisms arising from an impact event; intra-ply failure like fibre fracture and matrix cracking as well as inter-ply failure-like delamination. To achieve this, researchers often simulate a full composite laminate using a ply-by-ply approach where individual or bulk layers of a laminate stack are modelled using 3D continuum or shell elements. To capture progressive failure of the plies, continuum damage model (CDM) methods are adopted which degrade elements of a ply layer based on a suitable failure criterion model and the interface between each layer is simulated using cohesive zone modelling (CZM) methods. Numerous examples of this particular approach has been shown to simulate impact events [4-8]. Woven composites, which have proven to be more competitive than uni-directional (UD) laminates in impact resistance [9], are more challenging in the field of simulation modelling due to their complex woven fibre geometry. To achieve models that differentiate the warp and weft fibres, resin rich zones and the interfaces in-between is impractical. Even so, researchers often treat woven layers as a single bulk material with effective stiffness and strength properties similar to UD laminate layers. Due to the high level of detail in these modelling schemes, the computational cost of the simulations is extremely high and impractical when it comes to simulating larger structures subjected to impact events.

The main objective of the work presented herein is to investigate a macroscale modelling approach to simulate the damage formed on woven composites under high speed projectile impact also called ballistic impact. This will be achieved by treating the stacked woven composite laminate material as a single bulk material, with a single failure criterion with CDM used for simulating the total accumulated damage. The merit of this low-fidelity (LF) procedure will be compared to a standard high-fidelity (HF) ply-by-ply progressive failure with CZM to capture delamination. The key novelty of this work is the comparison of the two schemes in terms of computational speeds and accuracy in damage prediction. This type of comparison is not available in literature under a single investigation, since most research employ a single detailed modelling procedure often with bespoke user materials specifically written for it. To avoid this and make this work universal for both academic and industrial readers, commercial FE software package in LS-DYNA will be used in conjunction with built-in composite material model cards.

To aid with this study, experimental impacts were performed on woven composite plates to be used as benchmark cases for the numerical simulations. The experimental setup consisted of a gas gun able to project steel balls onto composite plate targets at various velocities prior and after the ballistic limit where full plate perforation was achieved.

\section{Experimental Methods}

The carbon fibre reinforced plastic (CFRP) composite material used for the ballistic impact experiments, was sourced from SHD Composites materials producer, denominated as MTC510-C380T-T700-12K-38\%RW. This is a toughened epoxy resin (MTC510) pre-impregnated fibre-matrix material system, reinforced by high strength carbon fibres (T700/12K). The fibres were twilled in a $2 \times 2$ weave style, shown in Figure 1, resulting in a fabric of $380 \mathrm{~g} / \mathrm{m}^{2}$ areal weight. The mechanical properties of the CFRP composite lamina are provided by the manufacturer, presented in Table 1. Plates of two different lay-ups were studied for the impact testing. The first configuration was orthotropic, having a lay-up arrangement of $\left[(0 / 90)_{4}\right]_{s}$ denominated as $[(0 / 90)]$ onwards for simplicity, while the second was quasi-isotropic with a layup arrangement of $[( \pm 45),(0 / 90),( \pm 45),(0 / 90)]_{s}$, denominated as $[( \pm 45)]$ onwards. Both configurations consisted of eight layers in total, providing specimens of nominal thickness of $3.6 \mathrm{~mm}$. In terms of the manufacturing procedure followed, the woven pre-impregnated layers were hand laid to create two $300 \mathrm{~mm}$ square laminate stacks. A de-bulking procedure under vacuum took place for every four plies, to consolidate the lay-up and remove all air trapped in the resin matrix. The laminates were 
cured in an autoclave according to the manufacturer specifications. Out of the two original $300 \mathrm{~mm}$ cured plates, four $150 \mathrm{~mm}$ square panels were machined, resulting to eight test specimens in total, four for each configuration.
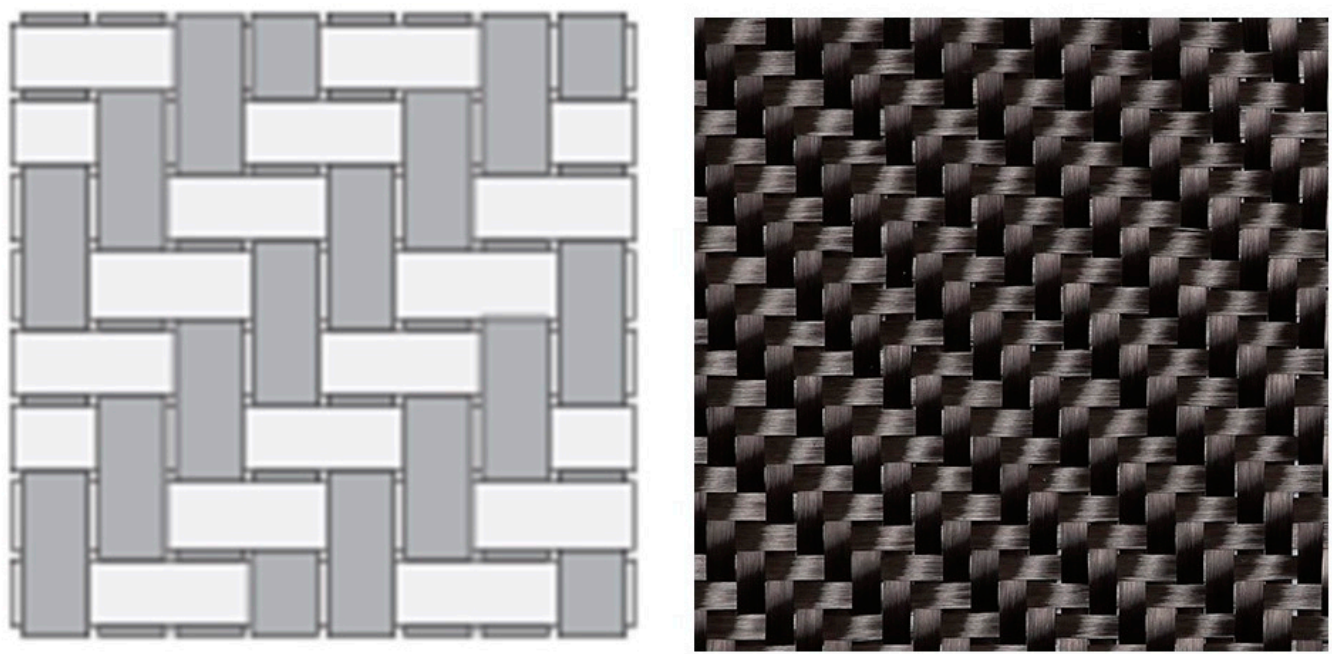

Figure 1. Twill weaving style of the MTC510 woven CFRP fabric.

Table 1. Material properties of the $2 \times 2$ twill woven CFRP system.

\begin{tabular}{cccc}
\hline Test & Results & Test Method \\
\hline \multirow{2}{*}{ Tension $0^{\circ}$} & Tension Strength & $1040 \mathrm{MPa}$ & \multirow{2}{*}{ Tension Modulus } \\
& Poisson's Ration & $\begin{array}{c}56.5 \mathrm{GPa} \\
0.05\end{array}$ & BS EN ISO 524-4 \\
& Compressive Strength & $572 \mathrm{MPa}$ & \multirow{2}{*}{ prEN 2850 Type B } \\
& Compressive Modulus & $49.1 \mathrm{GPa}$ & \multirow{2}{*}{ EN 6031 } \\
\hline \multirow{2}{*}{ Compression $0^{\circ}$} & In-Plane Shear Strength & $99 \mathrm{MPa}$ & \multirow{2}{*}{ BS EN ISO 14130 } \\
& In-Plane Shear Modulus & $3.43 \mathrm{GPa}$ & \\
\hline \multirow{2}{*}{ Interlaminar } & Interlaminar & $57.1 \mathrm{MPa}$ & \\
Shear Strength $0^{\circ}$ & Shear Strength & &
\end{tabular}

The ballistic impact experiments were conducted using a pressurised gas-gun set up as shown on Figure 2a. The aim of this experimental tests is to collect empirical data to assist with the low and high-fidelity modelling procedures. To maintain simplicity in the test procedure, spherical steel projectile were used instead of more complicated projectiles defined in available test standards. The impactors were stainless-steel balls with diameter of $12 \mathrm{~mm}$ and mass of $7 \mathrm{~g}$. The balls were loaded into the gun with the help of a $50 \mathrm{~g}$ polycarbonate sabot, placed at the end of the gun barrel. During the firing stage, the sabot was separated from the steel balls upon entry into the impact chamber from the exit nozzle. This effectively allowed only the steel ball to impact the FRP panels. The total mass of the sabot and steel ball ( $57 \mathrm{~g}$ ) was used to calculate the gas pressure in the gun to achieve the desired nominal impact velocity. The $150 \mathrm{~mm}$ square panels were mounted inside the impact chamber by clamping in the top and the bottom side, as shown in Figure 2b. The velocity of the impact was measured by a laser gate and the whole incident was captured with a high-speed camera. Limitations in number of samples only allowed for four different impact velocities per plate type. To generate useful trend, the impact velocities for the experiment were selected under, close to, and over the ballistic limit signified by plate perforation, to investigate the capability of the numerical model to predict the damage in each case. The ballistic limit was identified to be in the vicinity of $100 \mathrm{~m} / \mathrm{s}$. The velocity of the impactor was easily manipulated by the pressure of the gas in the gas-gun. The final parameters selected for the experiments are given on Table 2 . There 
were small deviations between the predicted and actual velocity impacting the targets. The actual velocities measured by the laser gate along with the associated energies of each impact are summarised in the results section of this work.
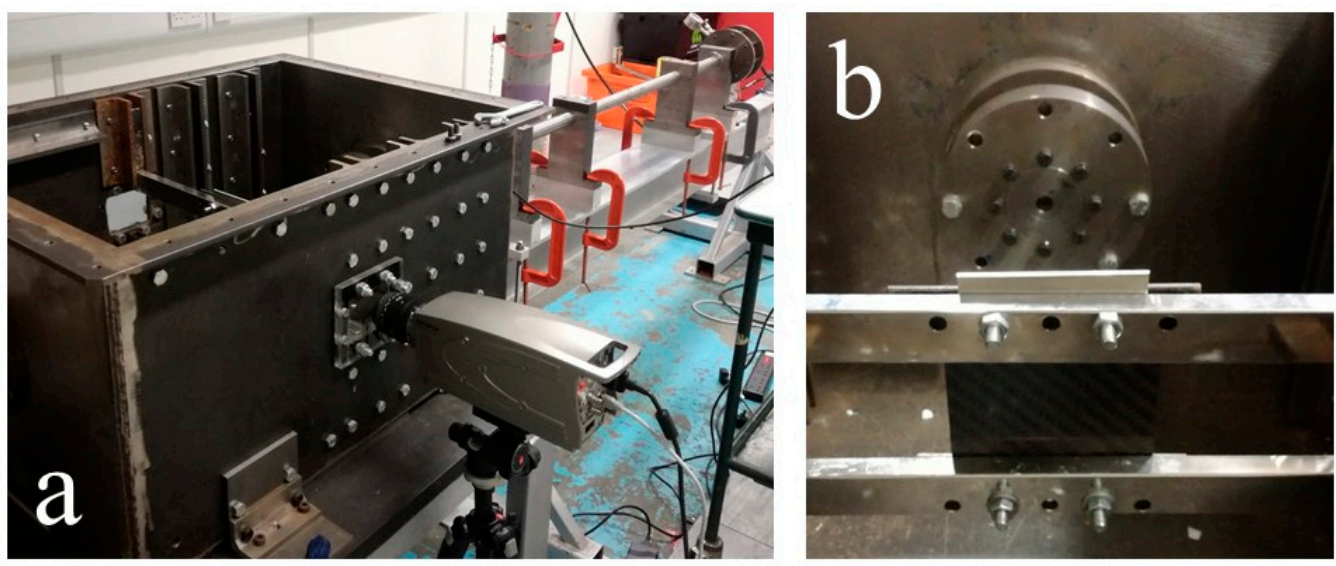

Figure 2. (a) Pressurised gun set-up, (b) exit nozzle and test panel-clamping arrangement.

Table 2. Impact velocities and energies selected for the experiments.

\begin{tabular}{ccc}
\hline Velocity $[\mathrm{m} / \mathrm{s}]$ & Energy $[\mathrm{J}]$ & Pressure [bar] \\
\hline 55 & 10.5 & 2 \\
\hline 100 & 35 & 5 \\
\hline 170 & 101.1 & 17.5 \\
\hline 210 & 154.3 & 25 \\
\hline
\end{tabular}

\section{Numerical Methods}

Numerical simulations have been carried out using the commercial software LSDYNAC. A high fidelity (HF) model version of the composite panels was created, where each ply was represented as an individual layer of shell elements with two integration points along the thickness direction for each element layer, shown in Figure 3a. Each layer was modelled with $0.5 \mathrm{~mm}$ size square solid shell elements, fully integrated formulation and a shell thickness of $0.45 \mathrm{~mm}$ per layer. The layers were bonded with each other with the TIEBREAK contact definition with CZM applied. The modelling approach was computational costly, but it allowed for the study of delamination between individual plies of the panel. For the lower fidelity (LF) model, a single shell elements layer was created with eight integration points through the thickness, each representing a single lamina ply, shown in Figure 3b. Similarly, to the HF model, fully integrated $0.5 \mathrm{~mm}$ square solid shell elements were defined.

Progressive damage modelling was implemented through in-plane continuum damage modelling on the woven fabric and discrete damage modelling for the inter laminar regions. Material card MAT_54 was used for modelling the woven fabric, contained progressive failure modelling to simulate orthotropic composite laminates. The material model MAT_54 was originally created for simulating unidirectional composite laminates but can be also applied on fabric composites following some assumptions. The woven lamina was considered an orthotropic material in which the fibres are dominating the strength in both longitudinal and transverse direction. In the case of the $2 \times 2$ twill weave, the properties of the material were considered the same in both directions. In the elastic behaviour regime prior to damage initiation, the model used the stress-strain equations developed by Chang and Chang [10]. The Chang-Chang failure criterion used in this material model can be calibrated to describe the shape of the post initiation failure response, similar to plasticity in metals, hence the nonlinearity of the post-failure of a ply can be captured [11]. The failure 
criterion is similar to Hashin failure criterion [12] which includes four failure modes for the longitudinal and transverse direction for both tensile and compressive loads. LS-DYNA uses four history variables to express this criterion as failure flags which express tension and compression failure for fibre and matrix direction respectively. MAT_54 model in LS-DYNA has both stress and strain dependent post failure response allowing the user to define the shape of the progressive failure response of a continuum element. The user can then define whether the stiffness of the continuum element degrades to zero in a linear form or it assumes a stepwise form, akin to metal plasticity, where the stiffness is kept constant for increasing strain, until it reaches the final failure strain, where the element stiffness is degraded completely. In the transverse direction, the model allows the user to define only one strain failure parameter for both tension and compression and two different strength values which were the major drawbacks in the use of the MAT_54 model in describing the behaviour of fabric composite materials. Due to the limitation of being able to use only one parameter for the transverse failure behaviour of the material it was decided to input the largest of the two strain to failure values. Another drawback is that the model allows for input of a single modulus of elasticity for tension and compression. The material under investigation exhibits a small difference in the moduli of about $12 \%$ between the two directions. In our numerical study, the larger value of the two was used, hence providing a slightly less compliant behaviour for the layers under compression. The strength and strain input values of the model are shown on Table 3.
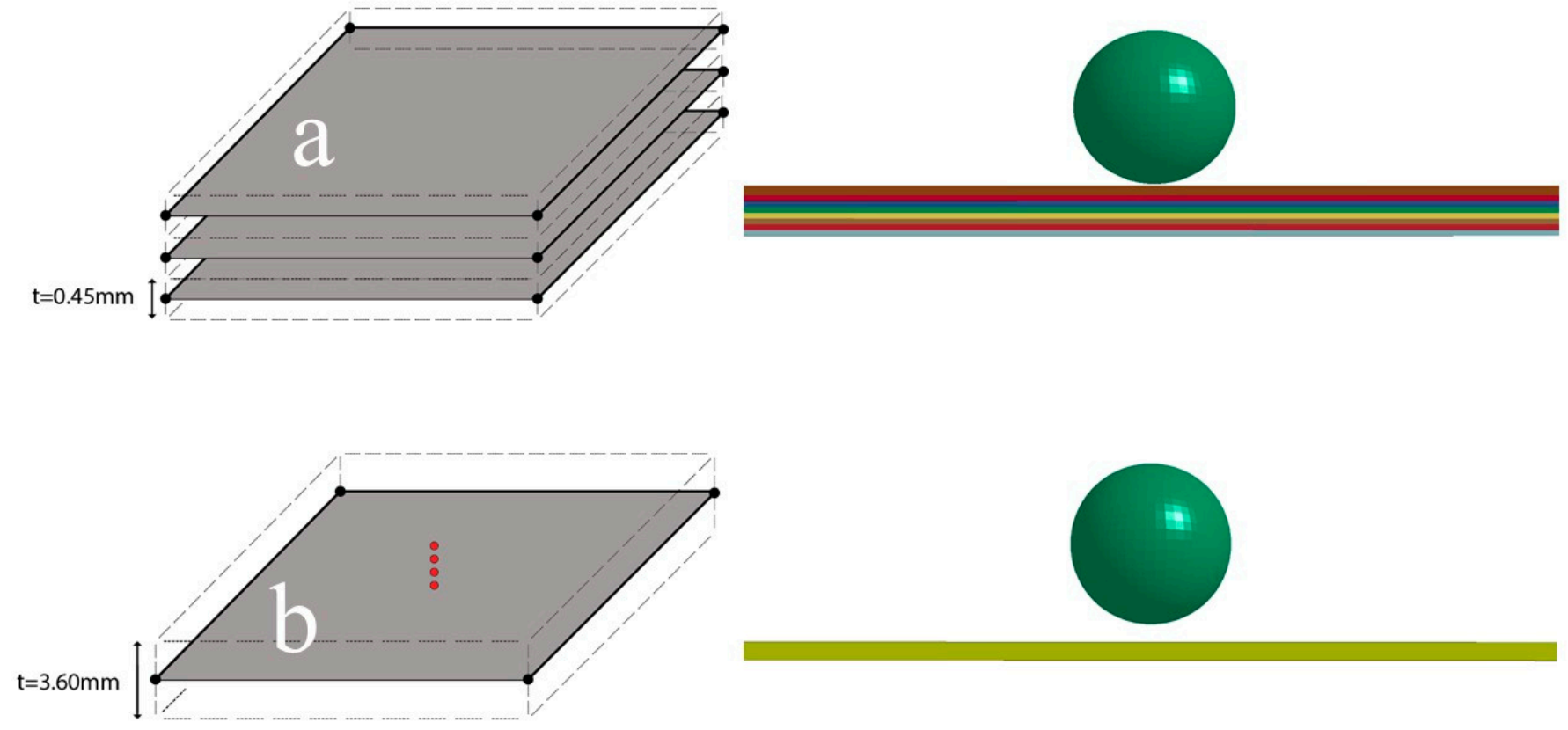

Figure 3. (a) High fidelity (HF) and (b) low fidelity (LF) model configuration.

Table 3. Failure initiation parameters for the $2 \times 2$ twill fabric using MAT_54.

\begin{tabular}{ccccc}
\hline & \multicolumn{2}{c}{ Strength } & \multicolumn{2}{c}{ Strain } \\
\hline \multirow{2}{*}{ Longitudinal } & $\mathrm{XT}$ & $\mathrm{XC}$ & DFAILT & DFAILC \\
\cline { 2 - 5 } & $1040 \mathrm{MPa}$ & $572 \mathrm{MPa}$ & 0.018 & 0.011 \\
\hline \multirow{2}{*}{ Transverse } & YT & YC & \multicolumn{2}{c}{ DFAILM } \\
\cline { 2 - 5 } & $1040 \mathrm{MPa}$ & $572 \mathrm{MPa}$ & \multicolumn{2}{c}{0.018} \\
\hline
\end{tabular}

To characterise and calibrate the behaviour of the material model, single element simulations have been conducted using the fully integrated shell element ELFORM 16. The results were put in comparison with experimental data from literature [13] to test the 
accuracy of the model at the element level where good agreement between experimental and simulation results was achieved as shown in Figure 4. Despite the drawback of only one strain to failure parameter in the transverse direction, the plastic behaviour of the material model until failure did not notably deviate from the experimental one. Adjusting the strain to failure parameters (DFAILT, DFAILC and DFAILM) effectively changes the fall of the slope post failure initiation (peak stress). The woven lamina can be considered as an orthotropic material in which the fibres are dominating the strength in both longitudinal and transverse direction, resulting in equal properties in these directions. This can be controlled by the DFAILM parameter, which originally describes the matrix behaviour of the UD material, only because UD composites tend to be matrix dominated in the transverse direction. In the case of the $2 \times 2$ twill weave, the properties of the material were considered the same in both directions. The limitation of having only one value (DFAILM) for the transverse failure behaviour of the material was overcame by inputting the biggest of the two strain to failure values (i.e., E22 compression strain to failure Figure 4 b.)
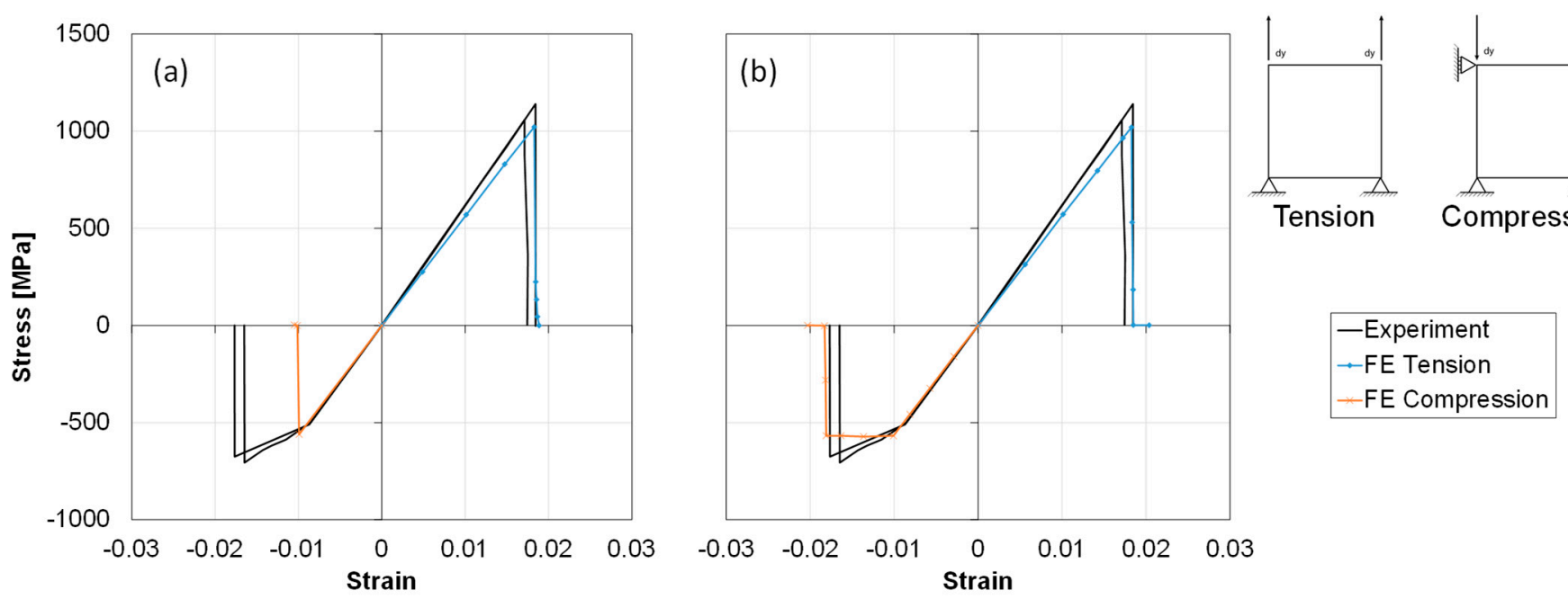

Figure 4. Stress vs. Strain curves of the single element simulation (a) in the longitudinal direction (E11) and (b) transverse direction compared to experimental results from [13].

For the inter laminar bond at ply interface, the HF models, automatic one-way surfaceto-surface TIEBREAK contact type was defined. The TIEBREAK contact allowed the connections to transfer both compressive and tensile forces [14]. The loads during contact were transferred from the slave nodes to the master segments through simple linear spring equations. CZM in the TIEBREAK contacts are described by a bilinear traction separation law, including a strength-based mixed mode failure initiation criterion between the surfaces and a quadratic mixed mode delamination criterion. For the damage initiation strength and failure propagation fracture toughness values, experimentally derived values from Kuwata and Hogg $[15,16]$ were used, where the woven FRP laminates are similar to those used in this study. The calibrated models are shown in Figure 5 which highlight the well matching response for double cantilever beam (DCB) tests and slight deviation with the end notch flexure (ENF) test in stiffness but close delamination initiation load. The CZM properties were calibrated with the experimental DCB and ENF tests results from the above-mentioned papers shown in Table 4. 

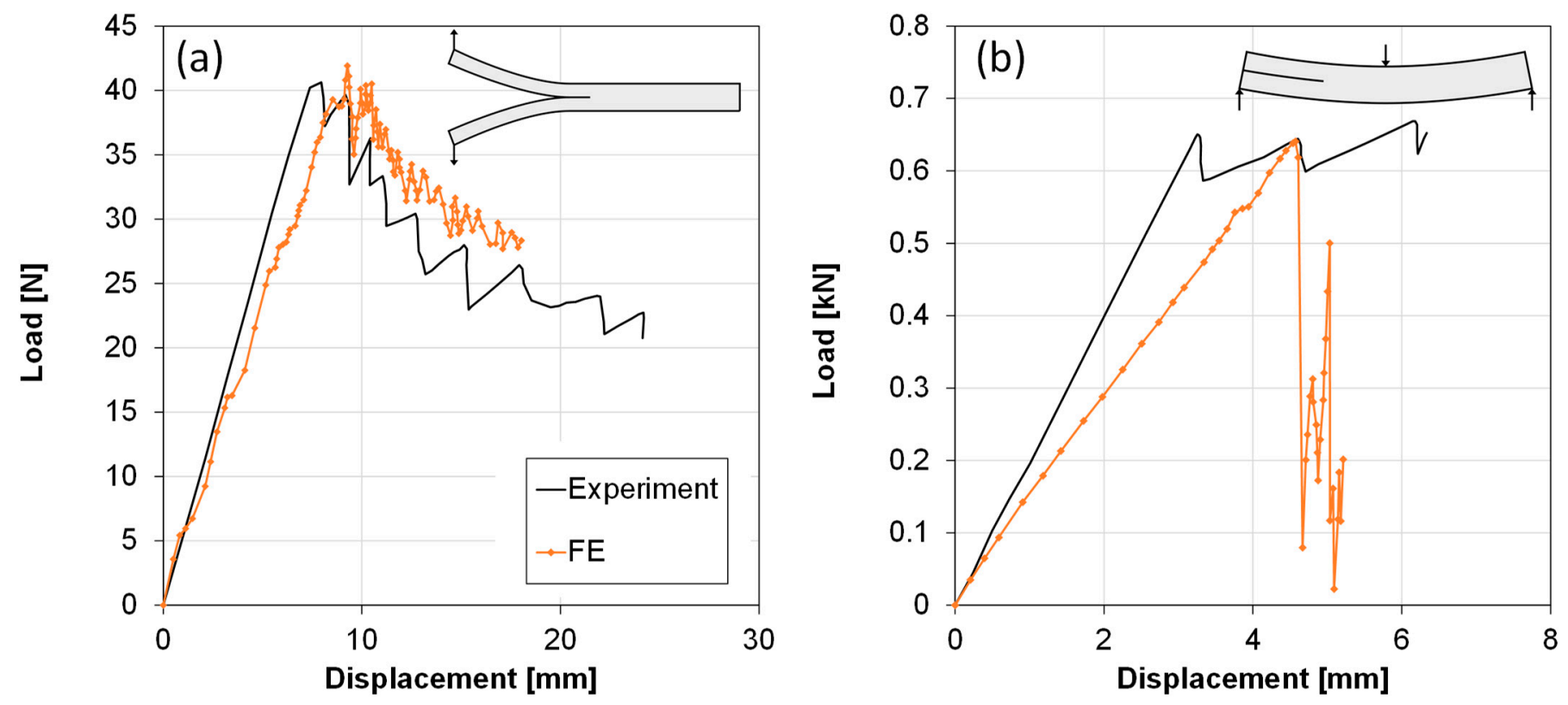

Figure 5. Load-displacement curves from (a) DCB and (b) 3ENF test simulation against experimental data from [15,16].

Table 4. Interlaminar damage imitation and propagation parameters calibrated with experimental results from $[15,16]$.

\begin{tabular}{ccc}
\hline LS-DYNA Parameter & Description & Value \\
\hline NFLS & Failure Stress for Mode-I & $35 \mathrm{MPa}$ \\
\hline ERATEN & Mode-I fracture toughness & $370 \mathrm{~kJ} / \mathrm{m}^{2}$ \\
\hline SFLS & Failure Stress for Mode-II & $57.1 \mathrm{MPa}$ \\
\hline ERATES & Mode-II fracture toughness & $1500 \mathrm{~kJ} / \mathrm{m}^{2}$ \\
\hline CN & Contact stiffness & $1014 \mathrm{~N} / \mathrm{m}^{3}$ \\
\hline
\end{tabular}

\section{Results}

\subsection{Visual and C-Scan Ultrasonic Inspection Results}

In total eight impact tests were conducted, four for each laminate configuration. Table 5 summarises the numbered tests along with the actual impact velocities measured. Following the impact testing, the specimens were subjected to visual inspection in terms of damage and perforation, as well as to ultrasonic C-scans testing for sketching out the interior damage extents. Typical impact failure mechanisms on woven composite plates include laminate damage (fibre tension fracture, matrix cracking) and delamination damage at laminate interfaces [17]. All impacts generated some delamination damage, whereas only at higher velocities laminate failures in form of fibre and matrix fractures were observed.

Table 5. Experimental parameters of the impact tests.

\begin{tabular}{|c|c|c|c|c|c|}
\hline Lay-Up & $\#$ & Impact Velocity [m/s] & Impact Energy [J] & Residual Velocity [m/s] & Absorbed Energy [J] \\
\hline \multirow{4}{*}{ Orthotropic $[(0 / 90)] 8 \mathrm{~s}$} & 1 & 52.6 & 9.7 & 0 & 9.7 \\
\hline & 2 & 97.2 & 33.0 & 0 & 33.0 \\
\hline & 3 & 177.1 & 109.7 & 120.2 & 50.6 \\
\hline & 4 & 211.5 & 156.5 & 162.3 & 92.2 \\
\hline \multirow{4}{*}{$\begin{array}{c}\text { Quasi-Isotropic } \\
{[( \pm 45),(0 / 90),( \pm 45),(0 / 90)] \mathrm{s}}\end{array}$} & 5 & 54.2 & 10.3 & 0 & 9.7 \\
\hline & 6 & 95.4 & 31.8 & 0 & 33.0 \\
\hline & 7 & 176.8 & 109.4 & 126.1 & 55.7 \\
\hline & 8 & 209.0 & 152.9 & 158.2 & 87.6 \\
\hline
\end{tabular}


For the lowest velocity impacts, in the vicinity of $50 \mathrm{~m} / \mathrm{s}$, neither perforation nor penetration of the panels were visually observed. A mark on the point that the impactor landed was visible on the front face of the panel, but the damage did not propagate to reach the back of the laminate, as shown in Figure 4. Some deviation in the impactor impact location was observed where the ball did not hit the laminate at the centre of the plate, as initially intended. Due to no perforation, the impact velocity was considered to be under the ballistic limit.

The next velocity regime of about $100 \mathrm{~m} / \mathrm{s}$ signified the observable damage on the outer surfaces of the laminate. Penetration of the impactor occurred for both laminate configurations. On the front face, a visible damage area appeared with matrix cracks travelling outwards from the impact point and towards the fibre direction. The deformation propagated all the way to the back of the panel, where fibre damage was obvious, with fibre bundles peeling off. The ballistic limit where full perforation of the impactor was expected had not been reached at this velocity, as shown in Figure 5.

Total perforation of the impactor occurred in the $170 \mathrm{~m} / \mathrm{s}$ velocity range for both configurations. Damage was clear at the front and back faces, as shown in Figure 6.
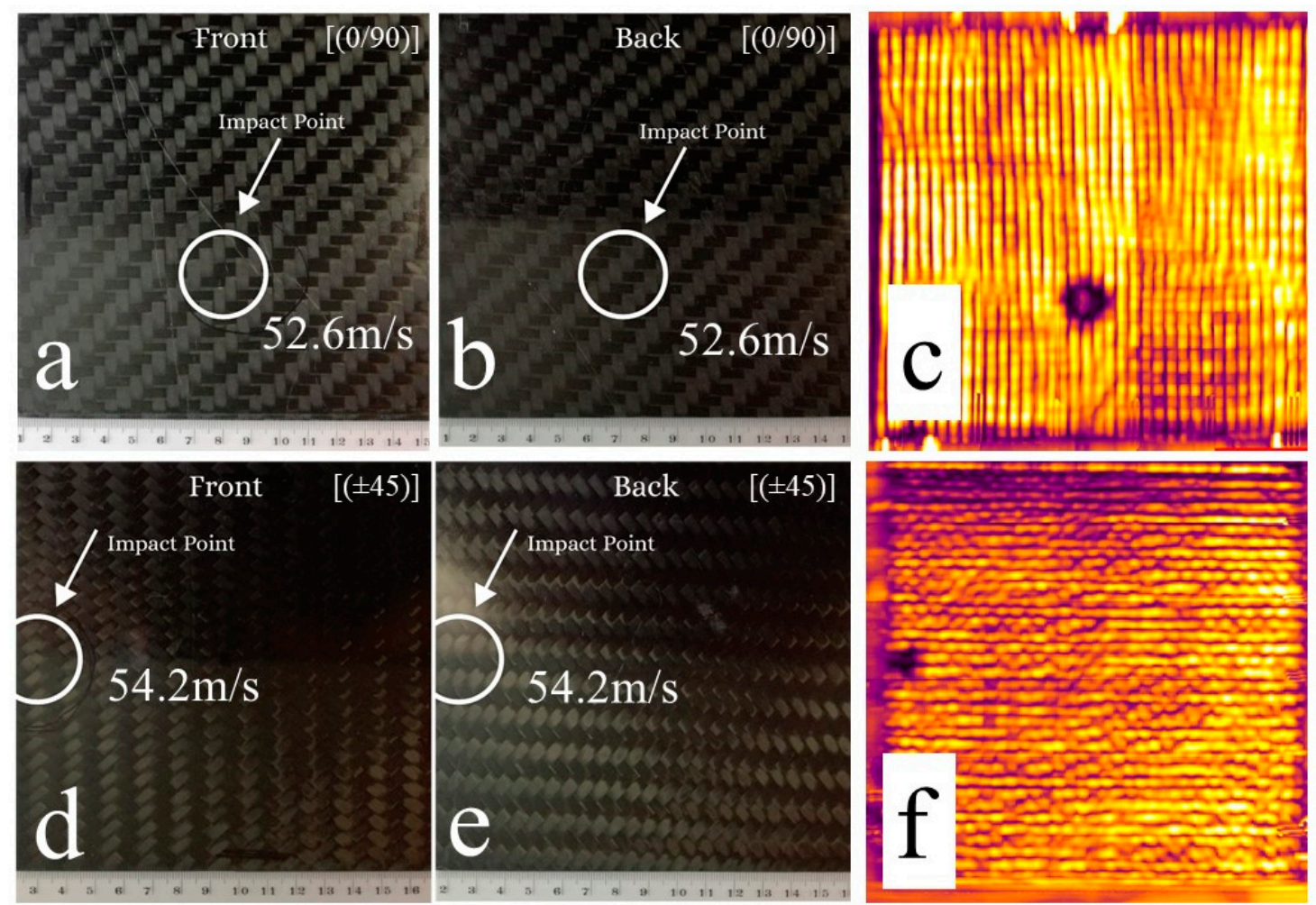

Figure 6. Visual and C-scan of $(\mathbf{a}-\mathbf{c})[(0 / 90)]$ at $52.6 \mathrm{~m} / \mathrm{s}$ and $(\mathbf{d}-\mathbf{f})[( \pm 45)]$ at $54.2 \mathrm{~m} / \mathrm{s}$.

The extent of the damage seemed to be greater at the back of the plate, where the ball exited from. Fibre breakage was exhibited, while bundles of fibres were coming out, without being detached from the plate nevertheless. Besides the noticeable perforated hole, matrix cracks were visible, initiating from the point of impact end expanding in the direction of the fibres for both cases.

Finally, the $210 \mathrm{~m} / \mathrm{s}$ level impacts are presented in Figure 7. In this velocity regime the perforation of the impactor left both panel configurations severely damaged. Material was permanently detached from the laminates and a pierced hole was visible all the way through the panel. The damage was larger in area extent for the [(0/90)] laminate.

The images obtained by the C-scans were analysed with the help of the image processing and analysing software Image-J. The internal damage extent was measured in terms of its width, length and area. In general, for both configurations, the damage extends 
increased with increasing impact energy, but with a decreasing rate of energy absorption hence damage increases. About $55 \%$ of the initial kinetic energy was absorbed for nominal impact velocity $177 \mathrm{~m} / \mathrm{s}$ shown in Figure 6, while only about $40 \%$ in the nominal impact velocity $210 \mathrm{~m} / \mathrm{s}$ in Figure 7 . The C-scans for the orthotropic laminates [(0/90)], revealed a damage shape that of a diamond unlike the $[( \pm 45)]$ ones, but both configurations revealed circular ones as the impact energy increased. In the case of the $[( \pm 45)]$ laminates, inspection revealed oval delaminated areas that expanded in an angle of $\pm 45^{\circ}$ across the plane of the panels.
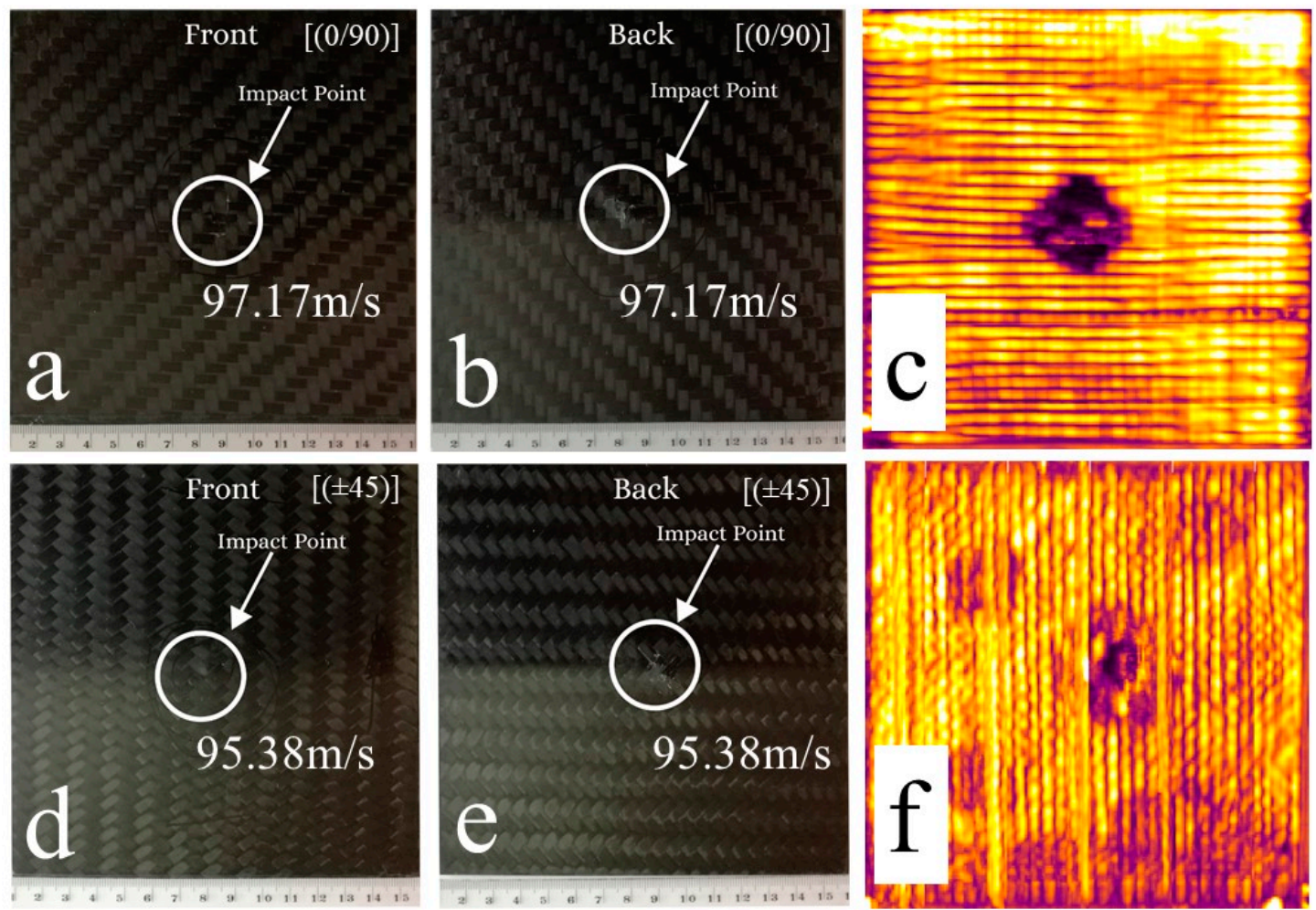

Figure 7. Visual and C-scan of $(\mathbf{a}-\mathbf{c})[(0 / 90)]$ at $97.2 \mathrm{~m} / \mathrm{s},(\mathbf{d}-\mathbf{f})[( \pm 45)]$ at $95.4 \mathrm{~m} / \mathrm{s}$.

\subsection{Numerical Simulation Results and Correlation with Experimental}

Following the experimental impact testing execution and samples visual and ultrasonic inspection, the experiments were numerically replicated with simulations having the exact same boundary and initial conditions. As the two lower energy experimental impact tests (9.68 J and 10.28 J) were not successful in impacting the plates at the centre, the results were discarded and were not repeated in simulations. In Figure 8, simulation and actual experiment stepped time frames are presented.

The simulation results from the HF and LF models model were processed in terms of damage. To investigate the accuracy of the HF model concerning the prediction of delamination damage, the results were compared with the ones of the experimental work. The HF model was capable of capturing the delaminations and were found similar to the ones from the C-Scans in terms of shape, though slightly smaller in total damage area, as shown on Figure 9.

In Figure 9, the delamination areas of the two configurations are plotted against each other where the better resistance to structural damage in terms of the delamination sizes and extends for the $[(0 / 90)]$ against the $[( \pm 45)]$ ones was visible. Although the damaged areas have satisfactory match with the experiments shape wise, the model appeared to under predict the extent of the damage in all of the cases where around $20 \%$ smaller damage areas were estimated, Figure 10. 

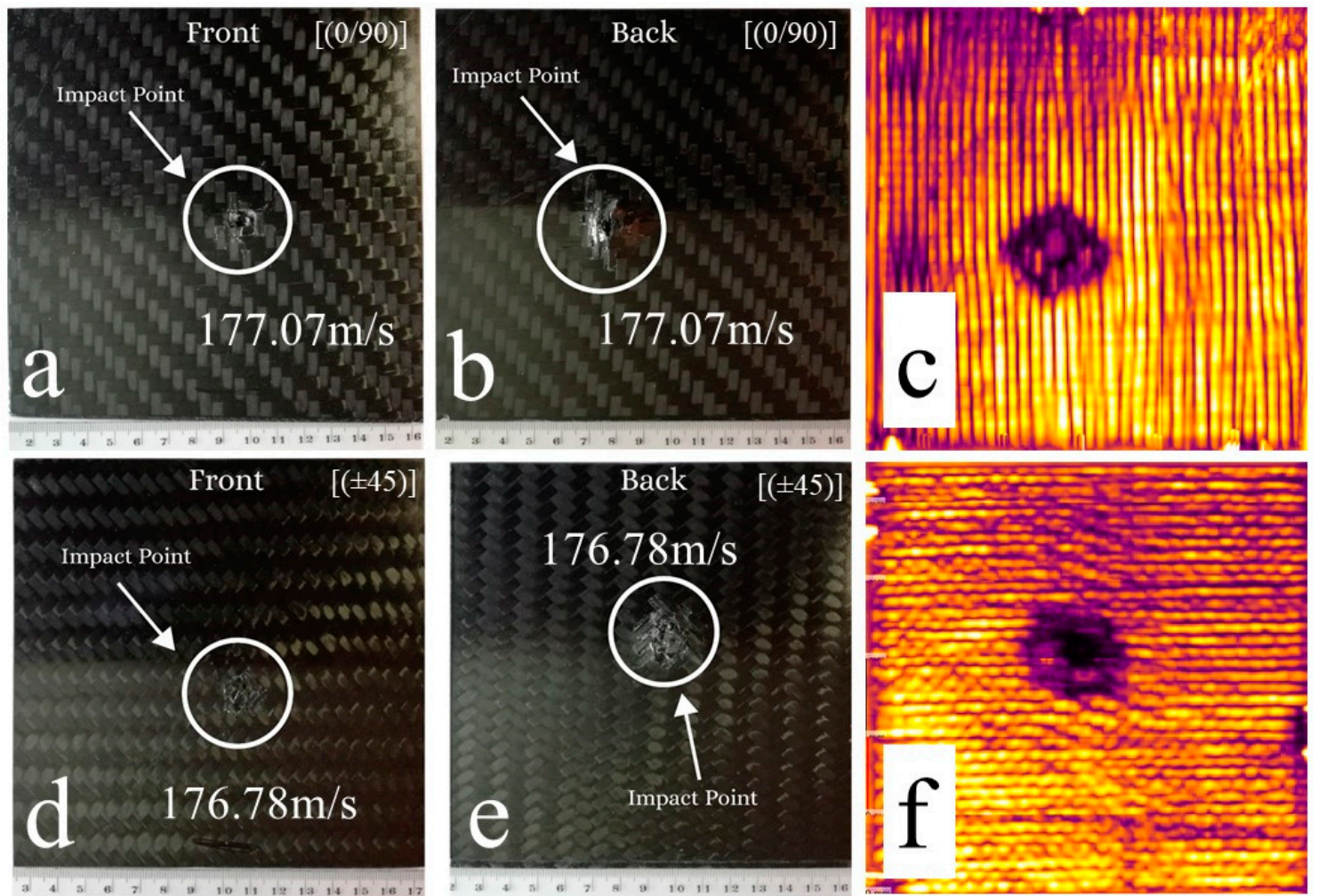

Figure 8. Visual and C-scan of $(\mathbf{a}-\mathbf{c})[(0 / 90)]$ at $177.1 \mathrm{~m} / \mathrm{s},(\mathbf{d}-\mathbf{f})[( \pm 45)]$ at $176.8 \mathrm{~m} / \mathrm{s}$.
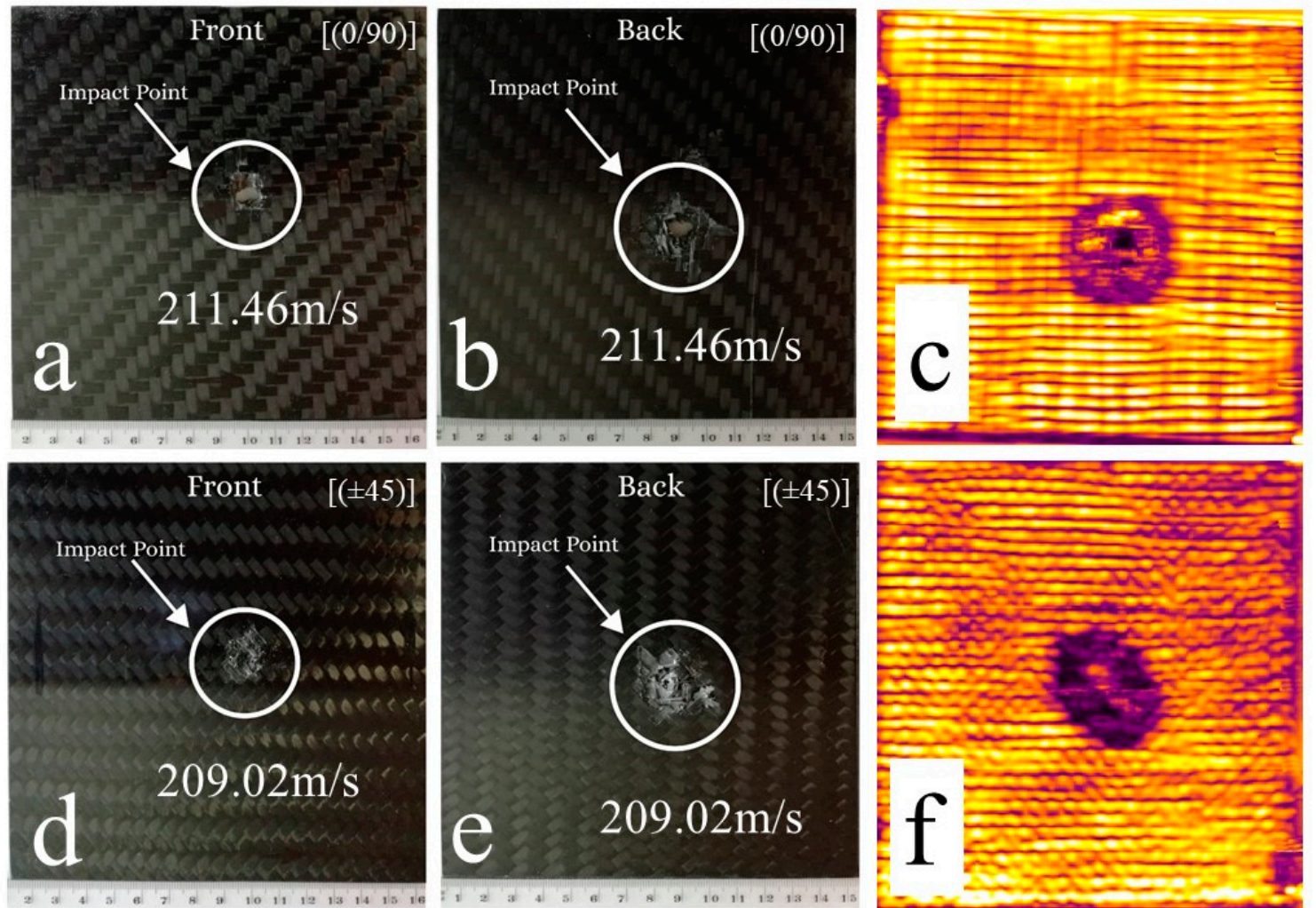

Figure 9. Visual and C-scan of $(\mathbf{a}-\mathbf{c})[(0 / 90)]$ at $211.45 \mathrm{~m} / \mathrm{s},(\mathbf{d}-\mathbf{f})[( \pm 45)]$ at $209.0 \mathrm{~m} / \mathrm{s}$. 


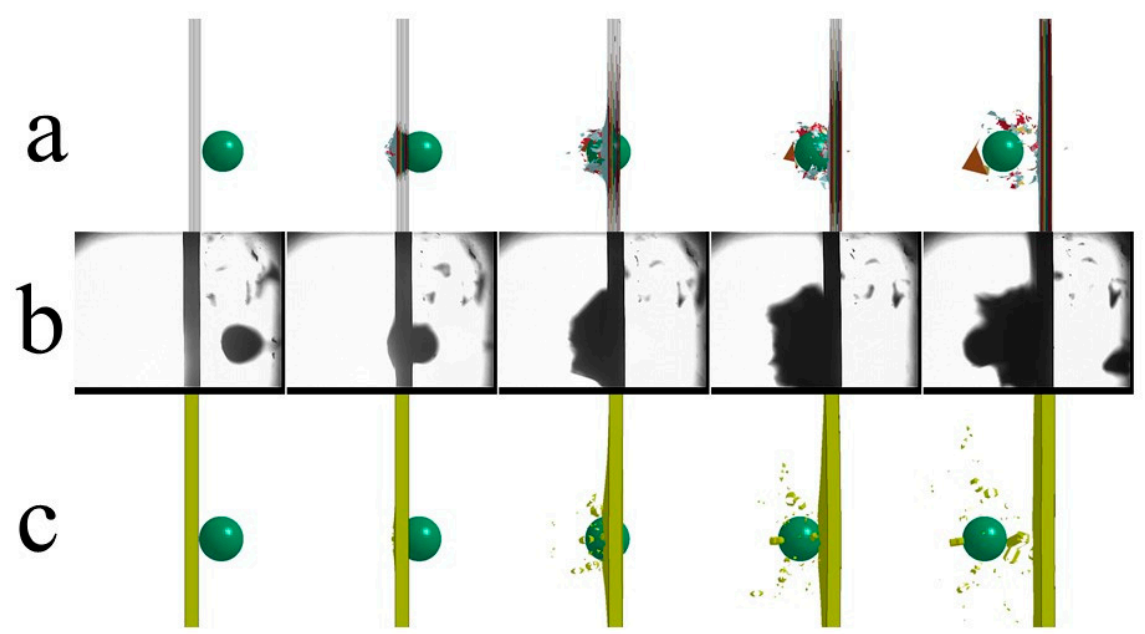

Figure 10. Ballistic impact time sequencing, (a) HF model, (b) high speed camera, (c) LF model.

The monotonically increasing trend of the delamination area as the energy of the impact increases, was preserved in the simulations results. Another interesting point of the HF model was to observe the shape of the damage through the thickness. The shape turned out to be consistent with the one proposed by [18] for laminates, as a cone shape of damaged area was formed from top to the bottom of the laminate, as shown in Figure 11.
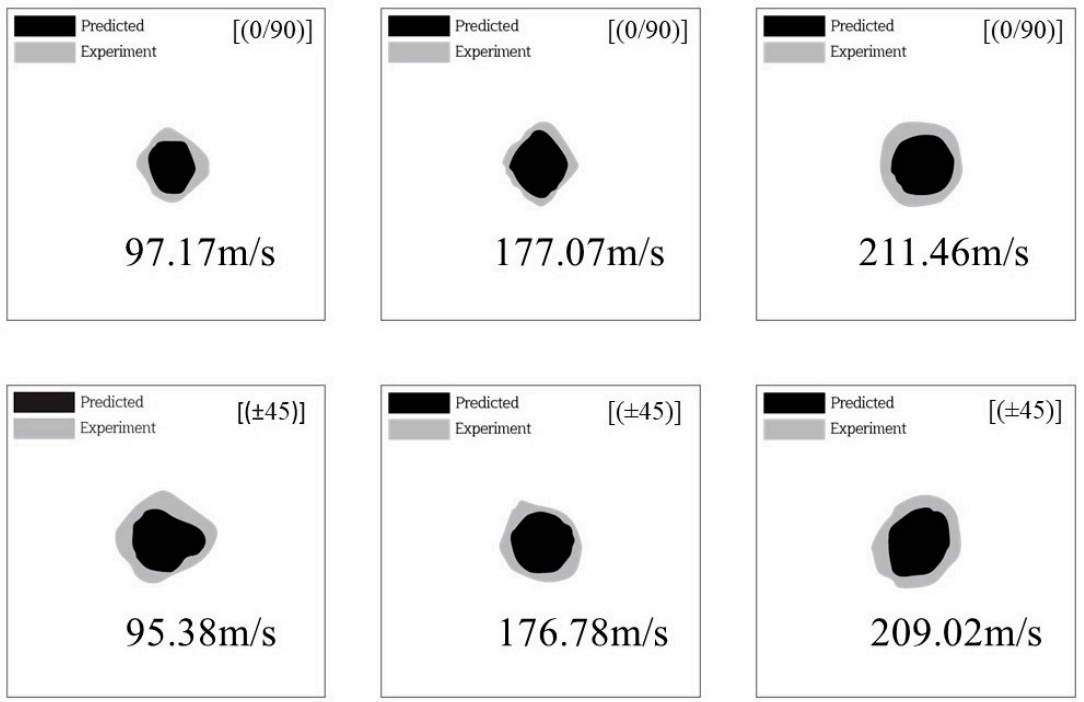

Figure 11. HF model numerically predicted and experimentally measured delamination areas superimposed.

The LF model simulation results were only in terms of intra laminar damage within the fabric. Shown in Figure 12, on the right are the representative tensile damage mode images for a single layer along the thickness the shell elements layer. In the HF model, the intra-laminar damage for each separate layer were of the same format but growing in size from top to bottom as per Figure 11. On the LF model, the damage outline in terms of deleted elements is the same and that of a single layer but having different damage fringe values for the different integration point. On Figures 12 and 13, the damage on the LF model is compared with the resulted experimental C-Scans and inter laminar damage extends from the HF model, where the similarities in the damage extend and shape are obvious. Figure 14 depicts the impact velocity versus delamination area for the experimental specimens and the HF numerical simulations.

A good measure in the capability of the numerical simulations to capture the event is by measuring the residual projectile velocity. The residual velocities of the steel ball impactors were measured experimentally and during the simulations. The residual velocities 
measured from the HF model simulations appeared to be higher than the experimental ones by almost $20 \%$, as shown in Figure 15 .

Less energy from the initial kinetic energy was transferred to the HF modelled plate in terms of plate deformation and material damage during the impact. The finding agreed with the under prediction of the damage by the HF model. On the other hand, the lower fidelity model appeared more consistent when it came to residual velocities, and an almost perfect match between simulations and experiments was observed. That variation in the behaviour of the models, led to the assumption that by inputting an artificial stiffness through the contact definition in the HF model, an error is incorporated in the total stiffness of the panel. The LF model lack this artificial stiffness, hence simulated reality better and the resistance that the plate showed to the impactor during the impact.
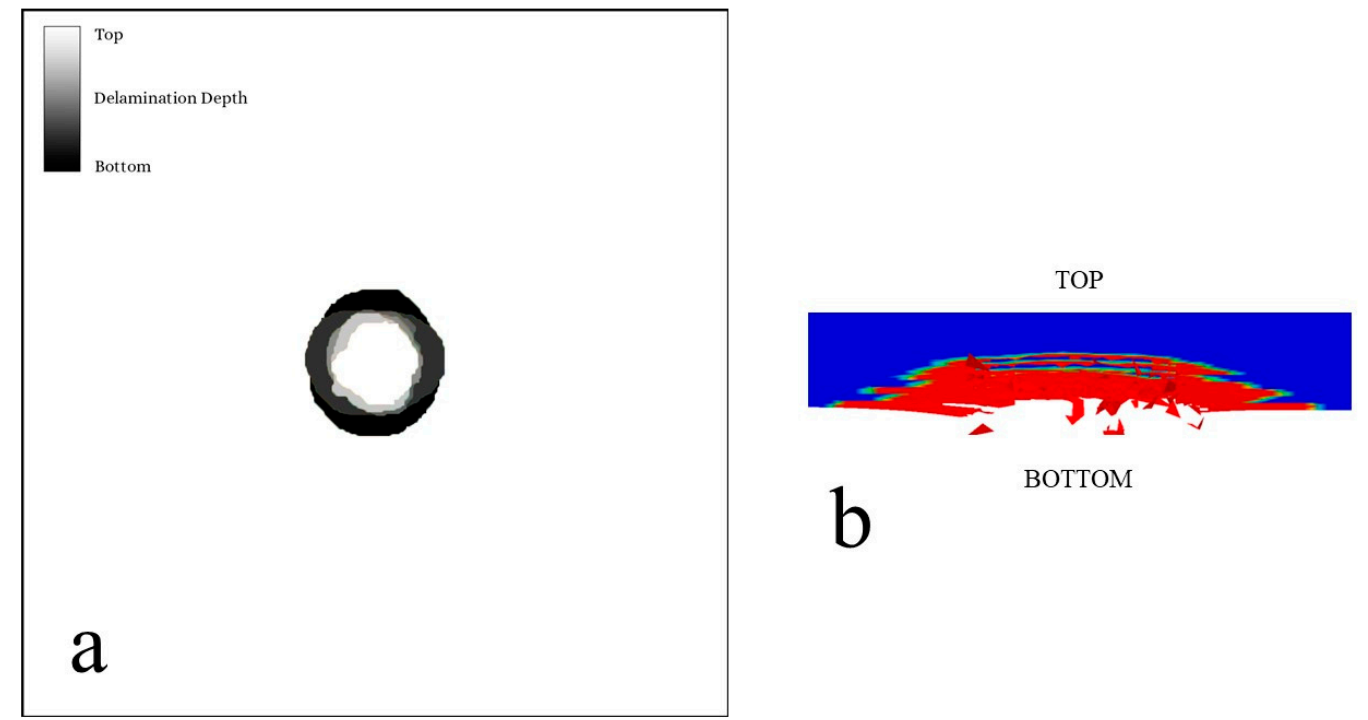

Figure 12. HF model numerically predicted inverted cone damage shape (a) inter-laminar delamination, (b) intra-laminar ply damage.
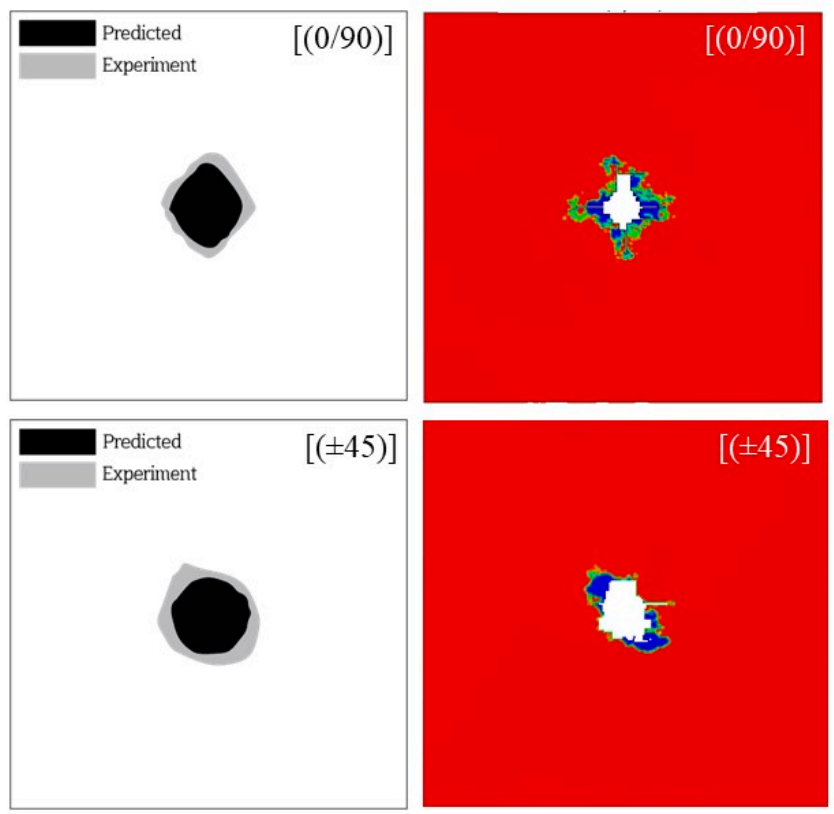

Figure 13. Contour of fibre tensile damage on the worst layer for the LF numerical models (right top and bottom) against the experimental C-Scans and the HF model inter laminar damage (left top and bottom). 


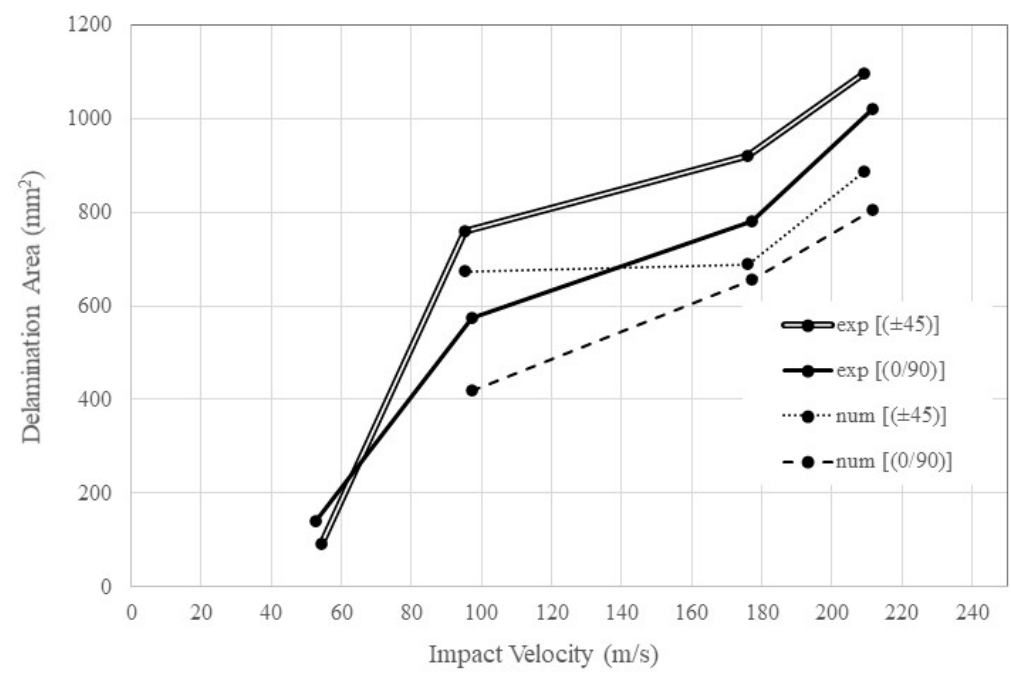

Figure 14. Impact velocity versus delamination area for the experimental specimens and the HF numerical simulations.

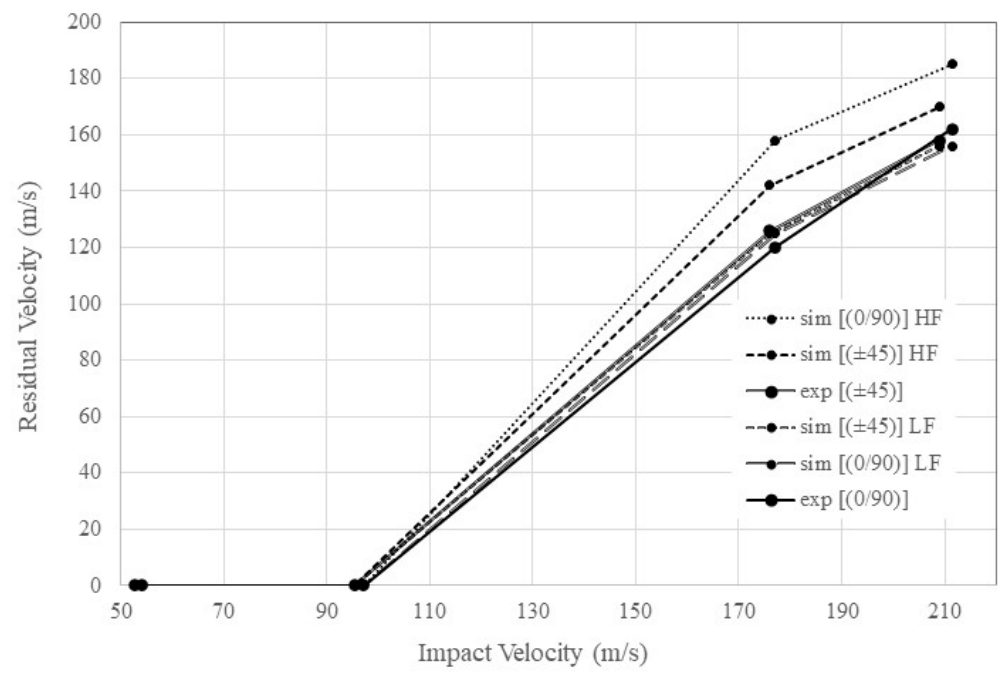

Figure 15. Steel ball impact velocity versus residual exit velocity from the plate target.

\section{Discussion}

In this work, we evaluated the damage prediction capability of two numerical modelling strategies, for ballistic impact of foreign objects onto composite woven CFRP targets. Initially, a number of experiments were performed that would later serve as benchmark studies for the numerical model results.

In terms of the experimental boundary conditions used in the study, the plates were attached onto an upper and a lower beam inside the impact chamber as shown in Figure $2 b$. Such boundary conditions were not of the ordinary square frame type most often used. This attachment is expected to have affected the damage extend results and the overall laminate behaviour, since in the $[(0 / 90)]$ for example, more layers were attached along the fibre direction onto the boundaries rather than in the case of the $[( \pm 45)]$ having inclined layers. For high-speed impacts though, the impact response is largely governed by the material behaviour close to the impact location. It is expected for the two laminate configurations to perform slightly differently in terms of the damage extends size if using different boundary conditions, as in the case of a square frame attachment for example. It is even expected for the $[( \pm 45)]$ to exhibit a better overall performance against damage accumulation. Although the $[(0 / 90)]$ configuration performed better in this study, the focus was to evaluate the behaviour of the numerical models. The HF models completed on average in $4.2 \mathrm{~h}$ on 
regular desktop PC whereas LF models completed on average in $0.8 \mathrm{~h}$. In terms of the numerical simulations, the HF model was able to capture inter as well as intra laminar damage at the expense of about $80 \%$ higher computational cost with respect to the LF one. The LF model was able to capture just the intra laminar damage, whilst it predicted the residual exit velocity of the projectile more precisely than the HF model. The HF model was numerically simulated and delaminations were found to be smaller from the experimentally measured ones. This deviation may be attributed to the fracture toughness values used and shown in Table 4, and was derived for similar fabrics but not the exact same one used herein. Although simulations took place to match the reported values with benchmark virtual tests, it is highly likely for the fracture toughness values of the specimens used in this study to be different. For ballistic type of impacts with significant higher energies than those in low velocity impacts, the major energy dissipation mechanisms can be attributed to fibre failure. The HF modelled inter-laminar delamination are not considered one of the major energy absorption mechanisms so the deviation in inter-laminar fracture toughness is not expected to have significant effect on the overall process. It is expected that the higher the energies involved during the impact, the lower the significance in the deviation of the inter-laminar fracture toughness in terms of damage energy absorption. This was evidenced during the HF and LF simulations, the LF model captured the overall energy absorption through the residual velocity in a much better way than the HF model. Of course, delamination modelling can be important if the damage extents need to be quantified for evaluating the plate residual strength, but it was evident that it did not contribute much to the overall impact energy absorption. An alternative model could be suggested as one that would contain a fewer number of inter laminar boundaries modelled, preferably close to the bottom of the plate, for capturing the damage extends. That would increase the damage detail extracted from a LF model, keeping in the same time the computational cost at a reasonable rate.

\section{Conclusions}

- The behaviour of ballistic impact of steel ball impactors onto CFRP woven fabric plates in terms of damage sizes and projectile residual strength was captured accurately enough with low fidelity models, avoiding the complexity of inter laminar damage modelling.

- The energy absorption mechanisms in the ballistic region were mainly related with fibre failure for the panel thickness tested resembling thin structural shell components of about $4 \mathrm{~mm}$ in thickness, hence even simpler, off the shelf constitutive progressive damage models based on simple failure and damage propagation laws were able to perform well.

- The application of inter laminar failure modelling in ballistic impact simulations onto FRP plates, can provide with more information in terms of damage, at the expense of computation cost and possible model accuracy due to the contact modelling artificial stiffness.

Although low-fidelity simulations are often overlooked in the simulation of impacted woven composite structures, in this investigation it was shown that this procedure can be useful to provide relatively good prediction of impact damage at $20 \%$ of the typical simulation times of a high-fidelity model, a certain benefit for both academic and industrial work requiring virtual testing of composite structures under impact.

Author Contributions: Conceptualisation, M.Y.; methodology, M.Y.; software, N.M.; validation, I.K.G., M.Y., and N.M.; formal analysis, N.M.; investigation, N.M.; resources, M.Y.; data curation, N.M.; writing—original draft preparation, I.K.G.; writing—review and editing, I.K.G. and M.Y.; supervision, M.Y. and I.K.G.; project administration, M.Y.; funding acquisition, M.Y. All authors have read and agreed to the published version of the manuscript.

Funding: This research received no external funding.

Institutional Review Board Statement: Not applicable for studies not involving humans or animals. 
Informed Consent Statement: Not applicable for studies not involving humans.

Data Availability Statement: The data presented in this study are contained within the article.

Acknowledgments: Not applicable.

Conflicts of Interest: The authors declare no conflict of interest.

\section{References}

1. Ferdous, W.; Manalo, A.; AlAjarmeh, O.; Mohammed, A.A.; Salih, C.; Yu, P.; Mehrinejad Khotbehsara, M.; Schubel, P. Static behaviour of glass fibre reinforced novel composite sleepers for mainline railway track. Eng. Struct. 2021, 229, 111627. [CrossRef]

2. Ferdous, W.; Manalo, A.; Peauril, J.; Salih, C.; Raghava Reddy, K.; Yu, P.; Schubel, P.; Heyer, T. Testing and modelling the fatigue behaviour of GFRP composites-Effect of stress level, stress concentration and frequency. Eng. Sci. Technol. Int. J. 2020, 23, 1223-1232. [CrossRef]

3. Abrate, S. Impact on Composite Structures; Cambridge University Press: Cambridge, UK, 2009.

4. Iannucci, L.; Willows, M.L. An energy based damage mechanics approach to modelling impact onto woven composite materialsPart I: Numerical models. Compos. Part A Appl. Sci. Manuf. 2006, 37, 2041-2056. [CrossRef]

5. Bresciani, L.M.; Manes, A.; Ruggiero, A.; Iannitti, G.; Giglio, M. Experimental tests and numerical modelling of ballistic impacts against Kevlar 29 plain-woven fabrics with an epoxy matrix: Macro-homogeneous and Meso-heterogeneous approaches. Compos. Part B Eng. 2016, 88, 114-130. [CrossRef]

6. Coles, L.A.; Roy, A.; Silberschmidt, V.V. Ice vs. steel: Ballistic impact of woven carbon/epoxy composites. Part II-Numerical modelling. Eng. Fract. Mech. 2020, 225, 106297. [CrossRef]

7. Johnson, H.E.; Louca, L.A.; Mouring, S.; Fallah, A.S. Modelling impact damage in marine composite panels. Int. J. Impact Eng. 2009, 36, 25-39. [CrossRef]

8. Arhore, E.G.; Yasaee, M. Lay-up optimisation of fibre-metal laminates panels for maximum impact absorption. J. Compos. Mater. 2020, 54, 4591-4609. [CrossRef]

9. Atas, C.; Sayman, O. An overall view on impact response of woven fabric composite plates. Compos. Struct. 2008, 82, 336-345. [CrossRef]

10. Chang, F.-K.; Chang, K.-Y. A Progressive Damage Model for Laminated Composites Containing Stress Concentrations. J. Compos. Mater. 1987, 21, 834-855. [CrossRef]

11. LS-DYNA Keyword User's Manual; Livermore Software Technology Corporation: Livermore, CA, USA, 2016.

12. Hashin, Z. Failure Criteria for Unidirectional Fiber Composites. J. Appl. Mech. 1980, 47, 329. [CrossRef]

13. Wade, B.; Feraboli, P.; Osborne, M.; Rassaian, M. Simulating Laminated Composite Materials Using LS-DYNA Material Model MAT54: Single-Element Investigation. U.S. Dep. Transp. 2015. Available online: https://www.researchgate.net/ publication/322152587_Simulating_Laminated_Composite_Materials_Using_LS-DYNA_Material_Model_MAT54_SingleElement_Investigation (accessed on 21 April 2021).

14. Tie-break contacts in LS-DYNA. Available online: https://www.d3view.com/wp-content/uploads/2007/09/tiebreak.pdf (accessed on 21 April 2021).

15. Kuwata, M.; Hogg, P.J. Interlaminar toughness of interleaved CFRP using non-woven veils: Part 1. Mode-I testing. Compos. Part A Appl. Sci. Manuf. 2011, 42, 1560-1570. [CrossRef]

16. Kuwata, M.; Hogg, P.J. Interlaminar toughness of interleaved CFRP using non-woven veils: Part 2. Mode-II testing. Compos. Part A Appl. Sci. Manuf. 2011, 42, 1560-1570. [CrossRef]

17. Zangana, S.; Epaarachchi, J.; Ferdous, W.; Leng, J. A novel hybridised composite sandwich core with Glass, Kevlar and Zylon fibres - Investigation under low-velocity impact. Int. J. Impact Eng. 2020, 137, 103430. [CrossRef]

18. Gellert, E.P.; Cimpoeru, S.J.; Woodward, R.L. Study of the effect of target thickness on the ballistic perforation of glass-fibrereinforced plastic composites. Int. J. Impact Eng. 2000, 24, 445-456. [CrossRef] 